University of Nebraska - Lincoln

DigitalCommons@University of Nebraska - Lincoln

\title{
Phytosanitary irradiation for export of fresh produce: commercial adoption in Hawaii and current issues
}

\author{
P. A. Follett \\ U.S. Pacific Basin Agricultural Research Center, USDA-ARS, peter.follett@ars.usda.gov \\ Marissa M. Wall \\ USDA-ARS
}

Follow this and additional works at: https://digitalcommons.unl.edu/usdaarsfacpub

Follett, P. A. and Wall, Marissa M., "Phytosanitary irradiation for export of fresh produce: commercial adoption in Hawaii and current issues" (2012). Publications from USDA-ARS / UNL Faculty. 1416. https://digitalcommons.unl.edu/usdaarsfacpub/1416

This Article is brought to you for free and open access by the U.S. Department of Agriculture: Agricultural Research Service, Lincoln, Nebraska at DigitalCommons@University of Nebraska - Lincoln. It has been accepted for inclusion in Publications from USDA-ARS / UNL Faculty by an authorized administrator of DigitalCommons@University of Nebraska - Lincoln. 


\title{
Phytosanitary irradiation for export of fresh produce: commercial adoption in Hawaii and current issues
}

\author{
Peter A. Follett • Marisa M. Wall
}

Received: 2 July 2012/Published online: 8 August 2012

(C) Akadémiai Kiadó, Budapest, Hungary 2012

\begin{abstract}
Hawaii is a pioneer in the use of phytosanitary irradiation. Irradiation is an approved treatment to control quarantine insect pests in 17 fruits and 7 vegetables for export from Hawaii to the US mainland. The commercial X-ray irradiation facility, Hawaii Pride LLC, has been shipping tropical fruits and vegetables to the US mainland using irradiation since 2000. Hawaiian purple sweet potato is the highest volume product with annual exports of more than 12 million lbs (5,500 tonnes). The advent of generic radiation treatments for tephritid fruit flies (150 Gy) and other insects (400 Gy) has accelerated commodity export approvals and facilitated adoption by foreign trading partners. Current impediments to wider adoption include the labeling requirement, the $1 \mathrm{kGy}$ limit for fresh horticultural products, and non-acceptance of phytosanitary irradiation in Japan and the European Union. USDA Animal and Plant Health Inspection Service (APHIS) has restricted the use of modified atmosphere packaging (MAP) for irradiated fresh fruits exported to the US due to possible increased radiotolerance in the target insects. Data are presented for response of melon fly in papaya to several types of MAP with radiation treatment at 45-65 Gy. Low oxygen atmospheres can increase insect radio-tolerance, but the effect is dependent on oxygen concentration and radiation dose.
\end{abstract}

P. A. Follett $(\varangle) \cdot$ M. M. Wall

US Pacific Basin Agricultural Research Center, USDA-ARS,

PO Box 4459, Hilo, HI 96720, USA

e-mail: peter.follett@ars.usda.gov
Keywords Phytosanitary treatment - Quarantine pests . Sweet potato $\cdot$ Generic doses $\cdot$ Labeling $\cdot$ Radiation

\section{Introduction}

World trade in agricultural commodities continues to grow. As agricultural trade expands, the risk increases of introducing exotic insects into new areas where they may become plant pests. The establishment of new pests can be costly due to increased crop damage, control programs, and quarantine restrictions on trade. Quarantine or phytosanitary treatments such as irradiation disinfest host commodities of insect pests before they are exported to areas where the pests do not occur, and are often the simplest approach to overcome regulatory trade barriers and gain market access.

\section{Low-dose radiation treatments}

The United States Food and Drug Administration (FDA) has approved radiation doses up to 1,000 Gy (1 kGy) for preservation and disinfestation of fresh fruits and vegetables [1]. Ionizing radiation breaks chemical bonds within DNA and other biomolecules, thereby disrupting normal cellular function in the infesting insect. Radio-tolerance can vary among the life stages of an insect [2], and between taxonomic groups of insects. Unlike other disinfestation techniques, irradiation does not need to kill the pest immediately to provide quarantine security, and therefore live (but sterile or not viable) insects may occur with the exported commodity [3]. The goal of a quarantine treatment is to prevent reproduction, and therefore the required response for a radiation treatment may be prevention of 
adult emergence [4], induction of adult sterility [5], or $\mathrm{F}_{1}$ sterility $[6,7]$.

\section{Commercial irradiation in Hawaii}

Hawaii was the first place in the world to use irradiation as a quarantine treatment of tropical fruits for export. In the early 1970s, commercial quantities of papayas were shipped from Hawaii to California and Florida to learn how handling and shipping might affect fruit quality [8]. Following the approval of irradiation by the FDA for control of insects in produce in 1986, a permit was issued for a one-time shipment of papayas from Hawaii to California to test for the first time consumer in-store response to irradiated food [9]. During the period from 1968 to 1986, numerous studies were conducted in Hawaii on the efficacy of radiation treatment against fruit flies and the effects of irradiation on the quality of tropical fruit crops [8]. Commercial shipments of fruit were carried out from 1995 to 2000 under a special use permit to demonstrate the feasibility of the technology to the tropical fruit industry. More than $300,000 \mathrm{~kg}$ (300 tonnes) of papayas and $100,000 \mathrm{~kg}$ (100 tonnes) of other fruits were shipped from Hawaii to the continental US for distribution in 16 states during this period [8]. In 2000, Hawaii Pride LLC (Keaau, Hawaii), the first commercial irradiation facility designed to treat fresh produce, opened for business on Hawaii island ("The Big Island") [10]. The source is a $5 \mathrm{MeV}$ electron linear accelerator (model TB-5/15, Titan Corp., San Diego, CA) with a 13,600 mt (30 million lbs) per year capacity. Hawaii Pride LLC is currently owned by Calavo Growers, Inc (Santa Paula, CA). The original business plan focused on papaya because a high volume of fruit is available year round. Their product line has diversified, and the facility presently irradiates sweet potatoes, papayas, dragon fruit, bananas, longan, rambutan, mangoes, curry leaf, and herbs such as sweet basil, before export to the US mainland. Hawaiian purple sweet potato is the highest volume product with annual exports of more than 12 million lbs (5,500 tonnes) [10]. A second irradiator, Pa'ina Hawaii, is under construction outside Honolulu on the island of Oahu. Pa'ina Hawaii is installing a Genesis irradiator (Grey Star, Inc., Mt. Arlington, NJ) that uses a cobalt-60 source. This is the first gamma irradiator specifically designed to process food.

\section{Research partnership leading to sweet potato exports}

Several years after opening, Hawaii Pride was in a critical financial situation as papaya production and exports were at a low point due to a prolonged drought. Hawaii Pride identified sweet potato as an opportunity to diversify their product line and generate new income. Hawaii's vegetable growers produce several unique varieties of sweet potatoes, including a purple-fleshed type. Methyl bromide was previously the only accepted quarantine treatment for sweet potatoes destined for export from Hawaii to the US mainland. Methyl bromide can cause damage to the sweet potato and had become increasingly costly, and therefore no sweet potatoes were being exported. Hawaii Pride petitioned the US Department of Agriculture (USDA) Animal and Plant Health Inspection Service (APHIS) to approve irradiation as a substitute treatment for methyl bromide, and the USDA Agricultural Research Service (ARS) began irradiation research with the key quarantine pests [5]. An irradiation treatment of $400 \mathrm{~Gy}$ for sweet potatoes was published as an interim rule in 2003 [11] and a final rule in 2004 [12] based on preliminary data on radiotolerance of three quarantine pests-sweet potato weevil, West Indian sweet potato weevil, and sweet potato vine borer-and an ARS recommendation for a high-dose. This was the first time USDA-APHIS considered the high-dose approach for controlling a pest complex until research is completed to confirm a lower dose. This $400 \mathrm{~Gy}$ treatment protocol was the precursor to a generic treatment for all insects (see discussion below). Sweet potato production doubled soon after the rule was published, and currently approximately 12 million lbs of sweet potatoes are exported using irradiation treatment. Eventually, research lowered the $400 \mathrm{~Gy}$ dose to $150 \mathrm{~Gy}$, resulting in a $60 \%$ cost savings to the commercial $\mathrm{X}$-ray radiation facility [5].

\section{Generic radiation doses}

In 2006, USDA-APHIS published a pioneering rule providing generic low-dose radiation quarantine treatments to control insects. A generic treatment is a single treatment that controls a broad group of pests without adversely affecting the quality of a wide range of commodities. The rule approved radiation doses of $150 \mathrm{~Gy}$ for any tephritid fruit fly and $400 \mathrm{~Gy}$ for all other insects except the pupa and adult stages of Lepidoptera (moths and butterflies) [13]. The generic radiation treatments apply to all fresh horticultural commodities. Therefore, if a pest risk assessment demonstrates that no pupae or adult Lepidoptera are associated with a commodity, export approval can be forthcoming with no further research. The logic behind generic doses is that information on radio-tolerance for a subset of species in a group can be extrapolated to related species to arrive at an effective generic dose. Traditionally, quarantine treatments are developed for one pest and commodity at a time, and research could take years to complete, so this first-ever approval of a generic treatment was a huge leap forward. 
Generic treatments are the culmination of decades of research but not an end point [14]. Future research will focus on development of specific doses for quarantine Lepidoptera not covered by the generic treatments (e.g. [15]); reduction of dose levels for specific pests and commodities to shorten treatment time [5]; development of generic doses below 400 Gy for important groups of quarantine arthropods other than fruit flies [14]; and development of information on commodity tolerance and novel methods to reduce injury and extend shelf-life [16-18].

\section{Research to lower doses}

Most fresh commodities traded between countries will initially make use of the 400 Gy generic dose due to the diversity of insect pests and the absence of information on radio-tolerance for each specific pest. Therefore, development of generic doses for groups of common plant pests other than fruit flies (e.g. mealy bugs, mites) would be beneficial [19]. If the dose can be lowered for a quarantine pest or group of pests, then the cost of treatment will be reduced, any quality problems will be minimized, and the capacity of the treatment facility may be increased owing to shorter treatment time [14].

The approved generic radiation treatment of $400 \mathrm{~Gy}$ excludes the pupa and adult stages of Lepidoptera [13]. Typically, exported fresh commodities that may contain pupae or adults of actionable lepidopteran pests must be inspected and found free of the pest before export is permitted, and their presence could result in rejection. Development of a radiation dose to control the lepidopteran pest would reduce inspections and prevent potential rejections of host commodities.

The radiation dose for a pest may also be lowered using a combination treatment. For example, Mediterranean fruit fly is controlled in clementine mandarins with a radiation dose of $30 \mathrm{~Gy}$ and subsequent exposure to $1{ }^{\circ} \mathrm{C}$ for 2 days [20], and oriental fruit fly and melon fly are controlled with 30 Gy and 6-9 days at 2-3 ${ }^{\circ} \mathrm{C}$ (Follett, unpublished data). These are significant reductions from both the approved generic radiation dose for fruit flies of $150 \mathrm{~Gy}$ and the standard cold quarantine treatments of $1.1-2.2{ }^{\circ} \mathrm{C}$ for 14-18 days. Cold is a convenient combination treatment with irradiation for commodities that are shipped with refrigeration.

\section{Trade facilitation}

Generic treatments will facilitate safe trade between countries that have approved the use of irradiation as a phytosanitary treatment. Irradiation is an approved treatment to control quarantine pests in 17 fruits and 7 vegetables for export from Hawaii to the US mainland $[3,10]$. During the past 5 years, India, Mexico, Pakistan, South Africa, Thailand, South Africa and Vietnam and have received approvals to export fruits to the US using generic radiation treatments. In 2009, the International Plant Protection Commission approved the generic radiation dose of $150 \mathrm{~Gy}$ for tephritid fruit flies, which will facilitate worldwide adoption [21]. The availability of generic dose treatments makes irradiation an attractive option compared to other quarantine treatments.

\section{Current issues}

Several issues present barriers to the wider use of phytosanitary irradiation. Labeling is an impediment to the marketing of irradiated fresh produce. In the US irradiated whole foods or fresh horticultural products must be labeled with the radura symbol and as treated by irradiation, either on individual fruits or at the point of sale [22]. No other insect disinfestation process requires labeling. Phytosanitary treatments are applied to meet regulatory requirements that protect agriculture and the environment, but the treated product has no added value to the retailer or consumer. Retailers are reluctant to carry irradiated fruits and vegetables because the label implies a warning. In contrast, sanitary uses of irradiation result in a value-added product because food borne illness and spoilage organisms have been eliminated, and shelf life may have been extended. This food is safer to eat and therefore consumers are willing to pay a premium price. The FDA published a proposed rule in 2007 outlining changes to the labeling requirement for irradiated food. Publication of a final rule is overdue.

The 1 kGy limit established by the FDA has no scientific basis and serves no practical purpose. In reality, many fresh horticultural products show radiation injury at doses above $1 \mathrm{kGy}$, but commodities that can withstand doses above $1 \mathrm{kGy}$ without injury should not have to meet the requirements of an arbitrary ceiling. The $1 \mathrm{kGy}$ limit for phytosanitary uses should be raised to $3-5 \mathrm{kGy}$ or eliminated. This may be particularly useful when using existing irradiation facilities designed for another purpose (e.g. medical device sterilization) to treat fresh commodities at low doses. Due to a relatively high dose uniformity ratio (2.5 or $3: 1$ ) at such facilities, insect disinfestation at a minimum radiation dose of 400 Gy may result in a maximum dose above $1 \mathrm{kGy}$. Practically, the maximum dose that can be applied will be determined by commodity tolerance. For tolerant commodities, raising or eliminating the $1 \mathrm{kGy}$ limit will allow for a wider variety of product configurations and help guarantee economic feasibility. 
Irradiation is not a universally accepted phytosanitary treatment. Japan and Taiwan irradiate potatoes to inhibit sprouting, but do not permit the import of irradiated produce or other food products. The European Commission allows irradiation of spices, herbs and vegetable seasonings, but prohibits the use of irradiation as a phytosanitary measure by members of the European Union.

To date, irradiation is not being used to treat imported fresh produce. Hawaii imports $2 / 3$ of its fruits and vegetables, and these imports are an important source of new invasive plant pests. USDA-APHIS inspects passengers and cargo leaving Hawaii destined for the US mainland, but does not inspect products from the mainland destined for Hawaii. A potential use of irradiation is to disinfest imported food and prevent pest incursions. Radiation treatment of high risk commodities at a relatively low dose, e.g. $100 \mathrm{~Gy}$, would disinfest them of most insect pests while minimizing quality problems. The cost of radiation treatment of imports could be offset by a reduced need for inspection or by charging inspection fees.

Studies showing increased survival of irradiated insects under low oxygen conditions have raised concerns about the efficacy of approved radiation quarantine treatments when commodities are treated in modified atmosphere packaging (MAP). For most insects of quarantine concern, there is no information on response to radiation treatment under low oxygen conditions. USDA-APHIS has placed restrictions on the use of MAP in irradiated imported fresh commodities until further research is conducted to elucidate the relationship between oxygen concentration and radio-tolerance. A study of MAP effects on the radio-tolerance of an important quarantine pest in Hawaii is discussed below.

\section{Modified atmosphere packaging}

Modified atmosphere packaging (MAP) is used to prolong the shelf-life of fresh produce [23], and its use is increasing. With MAP, respiring fresh produce modifies the package atmosphere such that $\mathrm{CO}_{2}$ levels increase and $\mathrm{O}_{2}$ levels decrease below ambient air concentrations. Insects are known to exhibit higher radio-tolerance in low oxygen environments. MAP produces a low oxygen environment which may increase the radio-tolerance of quarantine pests on traded commodities. USDA-APHIS has placed a restriction on the use of MAP for irradiated fresh fruit imported into the US, prohibiting bags that produce $<18 \%$ $\mathrm{O}_{2}$ concentration. The effect of MAP on the radio-tolerance of melon fly, Bactrocera cucurbitae (Diptera: Tephritidae) in papaya was examined. Melon fly is a serious economic and quarantine pest in Hawaii, and the most radio-tolerant fruit fly of quarantine significance [4].

\section{Methods}

MAP tests were conducted using papayas artificially infested with a laboratory strain of melon fly. Laboratory flies used in tests were obtained from colonies maintained at USDA-ARS laboratory in Hilo, Hawaii, and were reared on standard diets for each species. Rearing conditions for the duration of the experiments were $25 \pm 2{ }^{\circ} \mathrm{C}$ and a photoperiod of 14:10 (L:D) h.

Mature third instars were used in all tests because this is the most radio-tolerant life stage found in fruit [4]. For each test, 100 third instars were artificially inoculated into ripe papayas (Kapoho Solo cultivar) and randomly assigned to the experimental treatment. Treatments were (1) MAP + irradiation (at 45-65 Gy), (2) irradiation alone, (3) MAP alone, or (4) no MAP and no irradiation. Three types of commercially available MAP products were tested, with target $\mathrm{O}_{2}$ concentrations of $1-3 \%$ (low density polyethylene, Ziplock ${ }^{\circledR}$ brand 1-gallon storage bag, SC Johnson, Racine WI), 3-8 \% (Xtend ${ }^{\circledR}$ PP61, StePac L.A. Ltd, Tefen, Israel), and $12-14 \%$ (Xtend $^{\circledR}$ PP53). The Xtend films are composed of a proprietary blend of polymers with microperforations to obtain the desired modified atmosphere. Each MAP product was tested individually and treatments were replicated eight times in each test. Approximately 18-24 h after placing fruit in bags, samples were transported to a nearby commercial irradiation facility (Hawaii Pride, Keaau, HI), and treated with a radiation dose of 45-65 Gy) using an electron linear accelerator (5 MeV, model TB-5/15, Titan Corp., San Diego, California). ROW dosimeters (Opti-chromic detectors, FWT70-83 M, Far West Technology, Goleta, California) were placed in control fruit in each replicate to measure dose variation. Dosimeters were read with an FWT-200 reader (Far West Technology, Goleta, California) at 600-nm absorbance. To minimize the dose uniformity ratio (the ratio of the maximum/minimum dose), wooden racks holding a single row of bagged and unbagged papayas were placed perpendicular to the X-ray beam and elevated by placement on a cardboard box positioned in the center of the carrier. The dose uniformity (or maximum-minimum) ratio was $\leq 1.05$ for all replicates.

Immediately after radiation treatment, bagged and unbagged fruit were returned to the laboratory. Approximately $2 \mathrm{~h}$ after irradiation treatment, measurements of $\mathrm{O}_{2}$ and $\mathrm{CO}_{2}$ concentrations in bags were taken using a headspace oxygen/carbon dioxide analyzer (Illinois Instruments model 6600, Johnsburg, IL). Gas measurements were made again $24 \mathrm{~h}$ later (42-48 $\mathrm{h}$ after placing fruit in bags). After measurement of gases the second time, infested papayas were removed from bags, placed in plastic containers, and held for pupal development and adult emergence. Development of all individuals following a test was monitored 


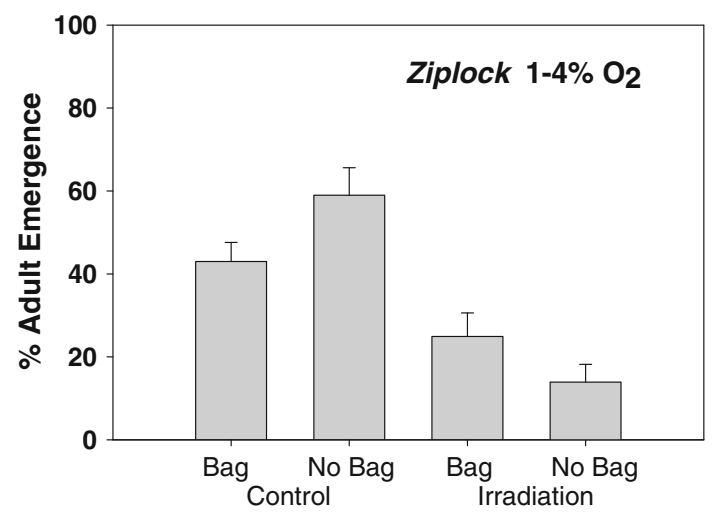

Fig. 1 Effect of modified atmosphere packaging (Ziplock Glad bag) and radiation treatment at $45-65$ Gy on melon fly maturation to the adult stage. Means $( \pm$ SE) are from 8 replicates of 100 larvae each

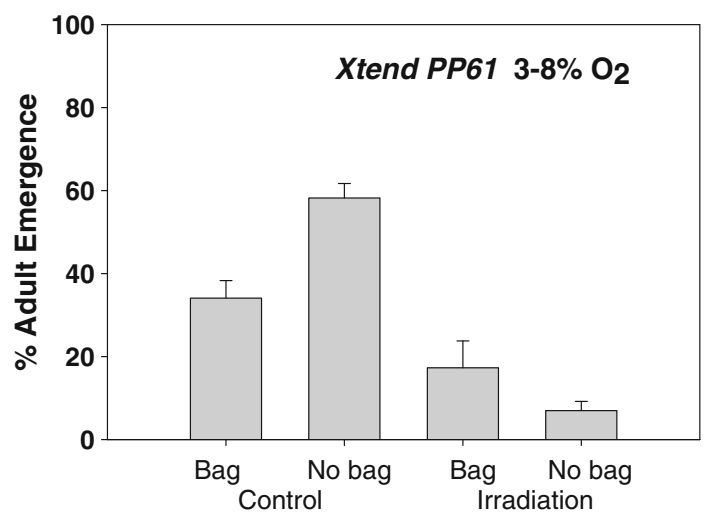

Fig. 2 Effect of modified atmosphere packaging (Xtend ${ }^{\circledR}$ PP 61 bag) and radiation treatment at $45-65$ Gy on melon fly maturation to the adult stage. Means $( \pm$ SE) are from 8 replicates of 100 larvae each

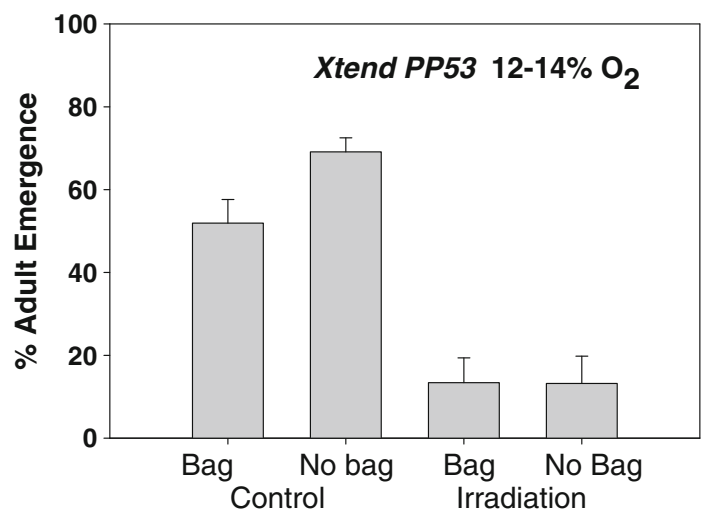

Fig. 3 Effect of modified atmosphere packaging (Xtend ${ }^{\circledR}$ PP 53 bag) and radiation treatment at 45-65 Gy on melon fly maturation to the adult stage. Means $( \pm$ SE) are from 8 replicates of 100 larvae each until death. Percentage adult emergence was the criterion used for comparing treatment effects.

\section{Results and discussion}

Placement of papayas infested with melon fly larvae in MAP bags without irradiation reduced survivorship to the adult stage compared with control fruit not placed in MAP bags (Figs. 1, 2, 3). This suggests that low $\mathrm{O}_{2}$ or elevated carbon dioxide is mildly toxic to melon fly larvae. Placement of infested papayas in Ziplock Glad bags $\left(1-3 \% \mathrm{O}_{2}\right)$ followed by irradiation significantly increased survivorship to adult stage from 10 to $20 \%$ (Fig. 1), demonstrating that low $\mathrm{O}_{2}$ can increase radio-tolerance in melon fly. Placement of infested papayas in Xtend PP61 bags $\left(3-8 \% \mathrm{O}_{2}\right)$ (Fig. 2) and Xtend PP53 bags $\left(12-16 \% \mathrm{O}_{2}\right.$ ) (Fig. 3) followed by irradiation did not enhance survivorship to the adult stage in melon fly. This suggests that increased radiotolerance during irradiation is dependent on $\mathrm{O}_{2}$ concentration, and that the USDA-APHIS prohibition on MAP producing $<18 \% \mathrm{O}_{2}$ may be too stringent. The radiation dose range of $45-65$ Gy was used to ensure that the treatments had survivors so that comparisons could be made. The APHIS-approved radiation dose for control of melon fly and other tephritid fruit flies is $150 \mathrm{~Gy}$. Largescale tests with melon flies inside papayas in Ziplock bags need to be conducted at 150 Gy to determine whether any survival is possible at this substantially higher radiation dose. In summary, MAP producing very low oxygen concentrations can increase melon fly survivorship during irradiation treatment, but it is not known whether these oxygen levels might compromise quarantine security at the higher doses used for quarantine control. Also, extremely low $\mathrm{O}_{2}$ levels are detrimental to many fruits, and in practice MAP producing 1-3\% $\mathrm{O}_{2}$ is avoided for fresh papaya and other fruits.

\section{References}

1. Food and Drug Administration (FDA) (1986) Irradiation in the production, processing, and handling of food. Fed Regist 51(75):13376, April 18, 1986. Rules and Regulations

2. Follett PA, Lower R (2000) Irradiation to ensure quarantine security for Cryptophlebia spp. (Lepidoptera: Tortricidae) in sapindaceous fruits from Hawaii. J Econ Entomol 93:1848-1854

3. Follett PA, Griffin R (2006) Irradiation as a phytosanitary treatment for fresh horticultural commodities: research and regulations. In: Sommers CH, Fan X (eds) Food irradiation research and technology. Blackwell, Oxford, pp 143-168

4. Follett PA, Armstrong JW (2004) Revised irradiation doses to control melon fly, Mediterranean fruit fly and oriental fruit fly (Diptera: Tephritidae) and a generic dose for tephritid fruit flies. J Econ Entomol 97:1254-1262 
5. Follett PA (2006) Irradiation as a methyl bromide alternative for postharvest control of Omphisa anastomosalis (Lepidoptera: Pyralidae) and Euscepes postfasciatus and Cylas formicarius elegantulus (Coleoptera: Curculionidae) in sweet potatoes. J Econ Entomol 99:32-37

6. Follett PA (2006) Irradiation as a phytosanitary treatment for Aspidiotus destructor (Homoptera: Diaspididae). J Econ Entomol 99:1138-1142

7. Follett PA (2006) Irradiation as a phytosanitary treatment for white peach scale (Homoptera: Diaspididae). J Econ Entomol 99:1974-1978

8. Moy JH, Wong L (2002) The efficacy and progress in using radiation as a quarantine treatment of tropical fruits - a case study in Hawaii. Rad Phys Chem 63:397-401

9. Bruhn CM, Noell JW (1987) Consumer in-store response to irradiated papayas. Food Technol pp. 83-85, Sept. 1987

10. Follett PA, Weinert ED (2012) Phytosanitary irradiation of tropical fresh commodities in Hawaii: generic treatments, commercial adoption, and current issues. Radiat Phys Chem. doi: 10.1016/j.radphyschem.2011.12.007

11. USDA-APHIS (2003) Irradiation of sweetpotatoes from Hawaii. Fed Regist 68(123):37931-37936, June 26, 2003. Rules and Regulations

12. USDA-APHIS (2004) Irradiation of sweetpotatoes from Hawaii. Fed Regist 69(32):7541-7547, February 18, 2004. Rules and Regulations

13. USDA-APHIS (2006) Treatments for fruits and vegetables. Fed Regist 71(18):4451, June 27, 2006. Rules and Regulations
14. Follett PA (2009) Generic radiation quarantine treatments: the next steps. J Econ Entomol 102:1399-1406

15. Hollingsworth RG, Follett PA (2007) Ionizing radiation for quarantine control of Opogona sacchari (Bojer) (Lepidoptera: Tineidae). J Econ Entomol 100:1519-1524

16. Morris SC, Jessup AJ (1994) Irradiation. In: Paull RE, Armstrong JW (eds) Insect pests and fresh horticultural products: treatments and responses. CAB International, Wallingford, pp 163-190

17. Wall MM (2008) Quality of postharvest horticultural crops after irradiation treatment. Stewart Postharvest Review 4(2):1, online at www.stewartpostharvest.com

18. Follett PA, Weinert E (2009) Comparative radiation dose mapping of single fruit type and mixed-fruit boxes for export from Hawaii. J Food Process Preserv 33:231-244

19. Follett PA, Neven LG (2006) Current trends in quarantine entomology. Annu Rev Entomol 51:359-385

20. Palou L, Del Rio MA, Marcilla A, Alonso M, Jacas JA (2007) Combined postharvest $\mathrm{x}$-ray and cold quarantine treatments against the Mediterranean fruit fly in 'Clemenules' 'mandarins'. Span J Agric Res 5:569-578

21. International Plant Protection Convention (IPPC) (2007) International Standards for Phytosanitary Measures (ISPM) No. 28, phytosanitary treatments for regulated pests. Irradiation treatments annexed 2009. FAO, Rome

22. Morehouse KM (2002) Food irradiation-US regulatory considerations. Rad Phys Chem 63:281-284

23. Yahia EM (1998) Modified and controlled atmospheres for tropical fruits. Hortic Rev 22:123-181 